\title{
Subjective worsening of memory predicts dementia after three years
}

\author{
Anne Brækhus, MD, Anne Rita Øksengård, MD, Knut Engedal, MD, PhD, \\ Knut Laake, MD, PhD
}

Research Group in Geriatrics of the Norwegian National Health Association, Ullevaal Hospital, 0407 Oslo, Norway

Correspondence: Dr. Anne Brækhus, Department of Geriatric Medicine, Ullevaal Hospital, 0407 Oslo, Norway

Telephone +4722118699 Telefax +4722118701 E-mail anne.brakhus@nordemens.no

\begin{abstract}
Study Objective: To assess whether complaining of memory impairment, as measured by the subjective part of the Geriatric Mental State examination (GMS, the Canberra community version), predicts later development of dementia.

Design: Prospective study of a random sample of older people with follow-ups after three, six, nine and twelve years.

Setting: Persons living at home.

Paricipants: 285 non-demented persons aged 75 years and above at start of study, $77.5 \%$ women.

Measurements: Dementia (DSM-III and DSM-III-R criteria).

Results: When adjusting for potential confounding by depressive symptoms, two of the GMS questions scored at baseline, 'Is it more difficult to remember things than it used to be?' and 'Do you write reminders to yourself more often now than before?', were significant predictors of dementia within three years, $\mathrm{OR}=3.3,95 \% \mathrm{CI}=1.2-8.6$ and $\mathrm{OR}=2.8,95 \% \mathrm{CI}=1.0-7.6$, respectively.

Conclusions: Elderly persons expressing a worsening of memory function are at increased risk of developing dementia.
\end{abstract}

Key words: aged, 75 years and over; subjective memory impairment; prospective study; dementia

\section{INTRODUCTION}

Complaints about reduced memory function are frequent among elderly people $(1,2)$. Associations between subjective memory loss and depression, depressed mood and certain personality traits have been demonstrated (3-5). However, studies of the relationship between a subjective feeling of a reduced memory function and objective memory impairment in elderly persons have led to ambiguous conclusions. Grut et al. (6) inferred that non-demented subjects with memory complaints perform less well on objective tests, while Hänninnen et al. (4) and Barker et al. (5) reported no correlation between perceived memory impairment and performance on memory tests. Nor did Christensen (7) find any association between memory complaints and test performance, except for those who felt that their memory was worse than their peers and worse than before, or had a poorer memory than predicted from their IQ.

Few studies have been carried out to examine whether subjective memory impairment predicts later development of dementia. Flicker (8) found that elder- ly people with a subjective perception of cognitive decrement were not at a high risk of worsened cognitive function during the subsequent 3-4 years. However, O'Brien et al. (9) showed that among subjects with memory complaints, nearly $10 \%$ developed dementia during the following three years.

The Canberra community version of the Geriatric Mental State examination (GMS, 10) consisted originally of five questions on perceived memory. This instrument was extended as suggested by Copeland (shown in Table 2) and applied at baseline in the Oslo study on mental health in the elderly, a populationbased study of the prevalence and incidence of dementia and depression in old age (11). In the present study, we have assessed whether these items predict later development of dementia.

\section{MATERIALS AND METHODS}

Data came from a prospective study of 334 subjects which began in 1984 and has been described in detail elsewhere (11). In the present paper, data from baseline (1984) and the follow-ups after 3, 6, 9, and 12 
years was utilized. Patients diagnosed as demented $(\mathrm{N}=35)$, with delirium or psychosis $(\mathrm{N}=2)$ at baseline were excluded, as well as 12 persons who could not be tested properly because of severely impaired vision, hearing or speech. Thus, 285 persons were included (Table 1). Their mean age at baseline $\left(\mathrm{T}_{0}\right)$ was 81.5 years (range 75-96), and there were 64 (22.5\%) males. Mean length of education was eight years (interquartile range 7-9). Dementia was diagnosed according to the DSM-III criteria (1984), whereas DSM-III-R was used at the follow-ups $(12,13)$. Table 1 shows a flow chart of the study.

Table 1. Flow chart of the study.

\begin{tabular}{|c|c|}
\hline \multicolumn{2}{|l|}{ At $T_{0}(1984 / 85)$} \\
\hline Included in the study (non-demented) & 285 \\
\hline \multicolumn{2}{|l|}{ At $T_{1}(1987 / 88)$} \\
\hline Dead between $T_{0}$ and $T_{1}$ & 62 \\
\hline Not possible to locate at $T_{1}$ & 10 \\
\hline Examined at $\mathrm{T}_{1}$ & 213 \\
\hline Diagnosed with dementia at $T_{1}$ (new cases) & 22 \\
\hline \multicolumn{2}{|l|}{ At $T_{2}(1990 / 91)$} \\
\hline Dead between $T_{1}$ and $T_{2}$ & 63 \\
\hline Not possible to locate at $T_{2}$ & 20 \\
\hline Examined at $\mathrm{T}_{2}$ & $130^{1}$ \\
\hline Diagnosed with dementia at $T_{2}$ (new cases) & 29 \\
\hline \multicolumn{2}{|l|}{ At $T_{3}(1994 / 95)$} \\
\hline Dead between $T_{2}$ and $T_{3}$ & 79 \\
\hline Not possible to locate at $T_{3}$ & 12 \\
\hline Examined at $\mathrm{T}_{3}$ & $59^{2}$ \\
\hline Diagnosed with dementia at $T_{3}$ (new cases) & 20 \\
\hline \multicolumn{2}{|l|}{ At $T_{4}(1997 / 98)$} \\
\hline Dead between $\mathrm{T}_{3}$ and $\mathrm{T}_{4}$ & 45 \\
\hline Not possible to locate at $T_{4}$ & 0 \\
\hline Examined at $\mathrm{T}_{4}$ & $26^{3}$ \\
\hline Diagnosed with dementia at $\mathrm{T}_{4}$ (new cases) & 12 \\
\hline \multicolumn{2}{|c|}{$\begin{array}{l}{ }^{1} \text { Only data from } 129 \text { cases used in the analyses, due to } \\
\text { missing data }\end{array}$} \\
\hline \multicolumn{2}{|c|}{$\begin{array}{l}{ }^{2} \text { Including persons lost to follow-up at } T_{2}(n=20) \\
\text { examined at } T_{3}\end{array}$} \\
\hline \multicolumn{2}{|c|}{$\begin{array}{l}{ }^{3} \text { Including persons lost to follow-up at } T_{2} \text { and } T \\
(n=12) \text {, examined at } T_{4}\end{array}$} \\
\hline
\end{tabular}

All respondents were assessed clinically and tested in their homes by the same physician (KE), who had long experience working with elderly people and also had special training in psychiatry (14). Perceived memory was scored at baseline using the subjective GMS items. Depressive symptoms were assessed using a modified and shortened version of the Beck Depression Inventory $(14,15)$. This contains items relating to mood, namely sadness, pessimism and loneliness. In a subsample consisting of 80 participants in the Oslo Study, the Montgomery and Aasberg depression scale (MADRS, 16) was also applied, and there was a high correlation between the modified Beck inventory and the MADRS sumscore $($ Pearson's correlation $=0.91)$ (in preparation).

Statistical analyses were performed with the BMDP and Epi-Info program packages $(17,18)$. Table analyses were applied to assess the relationship between age, gender, vision, hearing, education, depressive symptoms and perceived memory at baseline, expressed by tests of statistical significance (p-value). Bivariate table analyses were used to examine the association between the GMS items at baseline and later development of dementia expressed by odds ratio (OR) and a $95 \%$ confidence interval (CI), or by a test of statistical significance (p-value). Multivariate methods were applied to assess the association between GMS questions and later development of dementia and to adjust for potential confounding by depressive symptoms.

\section{RESULTS}

Table 2 shows the distribution of the responses to the GMS items at baseline. Having one or more memory problem was reported by $36.5 \%$. A substantial percentage reported forgetting where they had put things, that remembering things was more difficult than it used to be, or that they wrote reminders to themselves more frequently now than before. However, few complained about forgetting the names of family members or friends, forgetting to lock doors or to turn off the cooker, or to have problems with finding their way in well-known places.

For further analyses, we excluded items that received less than $5 \%$ positive responses in the baseline examination, as these would have a low sensitivity as markers of later dementia. This left four items for further analyses, i.e.: 'Do you forget things you've just read or heard?', 'Do you forget where you have put things?', 'Is it more difficult to remember things than it used to be?' and 'Do you write reminders to yourself more often now than before?'

\section{Correlates of perceived memory at baseline}

There was no statistically significant relationship between age at baseline (divided into three categories: $75-79,80-84$ and $85+$ years) and the responses to the four GMS items subjected to further analyses ( $p>0.08$ on chisquare for linear trend). Nor was there any association (analyses of $2 \times 2$ tables) with gender ( $p>0.30$ ), vision ( $p>0.347)$, hearing ( $>0.234)$ or length of education ( $p>0.220$ ), except for a positive relationship between the item concerning writing reminders and length of education $(\mathrm{p}=0.001)$.

The relationship between the four GMS items and the MMSE sumscore at baseline was analyzed after categorizing the sumscore into three bands (24-25, 26-28 and 29-30). No significant association was demonstrated $(\mathrm{p}>0.131$ on chisquare for linear trend for all analyses). 
Table 2. Respondents, non-demented at start of study, reporting memory problems at baseline, by GMS items, $\mathrm{N}=285$.

\begin{tabular}{llrr}
\hline & & \multicolumn{2}{c}{ Problem reported by } \\
\cline { 2 - 3 } & Item & $\mathrm{N}$ & $\%$ \\
\hline 1 & 'Have you had any difficulty with your memory?' & 11 & 3.9 \\
$2 *$ & 'Do you forget things you've just read or heard?' & 21 & 7.4 \\
3 & 'Do you forget names of family members or friends?' & 4 & 1.4 \\
$4 *$ & 'Do you forget where you have put things?' & 41 & 14.4 \\
5 & 'Do you forget to lock doors or turn off the cooker?' & 2 & 0.7 \\
6 & 'Can you remember the right word to use when you are speaking?' & 6 & 2.1 \\
7 & 'Is forgetfulness a problem for you?' & 12 & 4.2 \\
$8 *$ & 'Is it more difficult to remember things than it used to be?' & 97 & 34.0 \\
$9 *$ & 'Do you write reminders to yourself more often now than before?' & 59 & 20.7 \\
10 & 'Have you recently had problems with finding your way in well-known places?' & 2 & 0.7 \\
\hline
\end{tabular}

* Questions included in subsequent analyses.

The association between the score on each of the four GMS items and depressive symptoms was also studied by table analysis. A statistically significant relationship existed for all four GMS questions $(p<0.027$ on chisquare for linear trend for all analyses).

\section{Relationship between scoring on GMS items at base- line and new dementia diagnosed at follow-ups}

Bivariate analyses demonstrated an assosiation between new dementia occuring within three years $(\mathrm{N}=22$ out of 213 survivors examined) and two of the four GMS items at baseline: 'Is it more difficult to remember things than it used to be?' $(\mathrm{OR}=3.0$, $\mathrm{CI}=1.1-8.1$ ), and 'Do you write reminders to yourself more often now than before?' $(\mathrm{OR}=2.7, \mathrm{CI}=0.9-7.6$, Table 3 ). The predictive value of a confirmatory answer on these two items was 0.17 and 0.19 , respectively. There was no significant association between length of education and development of dementia.

No significant relationship was found (bivariate analyses) between any GMS item at baseline and new dementia developed during the periods 3-6, 6-9, and 912 years $(p>0.20)$ except for a statistically significant assosiation between 'Do you write reminders to yourself more often now than before?' and new dementia diagnosed at $\mathrm{T}_{3}$ (9 years after baseline, $\mathrm{p}=0.03$ ).

\section{Multivariate adjustment for confunding by depressive symptoms}

Depressive symptoms were related to the scoring on the four GMS items at baseline and also predicted dementia after three years $(\mathrm{OR}=3.9, \mathrm{CI}=1.3-12.1)$. Thus they were potential confounders of an association between perceived memory impairment at baseline and later dementia. To test for this, we carried out multiple logistic regression analyses with backward stepping, one model for each of the four GMS questions with $\mathrm{p}$ values $<0.10$ on the association between the GMS items at baseline and dementia after three years (cutpoint $2 / 3$ on the modified Beck inventory). The results showed a significant and independent association between new dementia within three years $(\mathrm{N}=22)$, after adjustment for depressive symptoms, and the following two questions: 'Is it more difficult to remember things than it used to be?' (adjusted $\mathrm{OR}=3.3, \mathrm{CI}=1.2-$ 8.6), and 'Do you write reminders to yourself more often now than before?' (adjusted $\mathrm{OR}=2.8, \mathrm{CI}=1.0$ 7.6). Both these questions had acceptable sensitivity (0.6 and 0.4$)$ and specificity (0.7 and 0.8$)$ as diagnostic markers regarding new dementia within three years, and were included in further analyses (Table 3).

\section{Risk assessment of developing dementia within three years by simultaneous use of GMS questions, the MMSE sumscore, and the modified Beck inventory}

Using this cohort, we have previously demonstrated that a low, though 'normal', MMSE sumscore (24-27) also is a significant predictor of new dementia within the next three years (19). Multiple logistic regression with backward stepping was carried out with an initial model consisting of the two remaining GMS items, the MMSE score divided into two bands (cutpoint 27/28) and the modified Beck inventory (cutpoint 2/3). This resulted in a final model containing the MMSE (adjusted $\mathrm{OR}=7.4, \mathrm{CI}=2.4-22.9$ ), the modified Beck score (adjusted $\mathrm{OR}=4.3, \mathrm{CI}=1.4-13.4$ ), and the GMS variable 'Is it more difficult to remember things now than it used to be?' (adjusted $\mathrm{OR}=3.8, \mathrm{CI}=1.4-10.8$ ). The probabilities of developing dementia within three years, depending simultaneously on subjective memory impairment, depressive symptoms and MMSE sumscore are presented in Table 4. 
Table 3. Scoring on the four GMS-items with high baseline prevalences of impairment at $T_{0}$ related to new dementia after three years $(\mathrm{N}=213)$.

\begin{tabular}{|c|c|c|c|c|c|c|c|c|}
\hline & & Demented & $\begin{array}{c}\text { Non- } \\
\text { demented }\end{array}$ & OR & $95 \% \mathrm{CI}$ & $\begin{array}{l}\text { Sensi- } \\
\text { tivity }\end{array}$ & $\begin{array}{l}\text { Speci- } \\
\text { ficity }\end{array}$ & $\begin{array}{l}\text { Likelihood } \\
\text { ratio } \\
\end{array}$ \\
\hline \multirow{2}{*}{$\begin{array}{l}\text { 'Do you forget things you have } \\
\text { just read or heard?' }\end{array}$} & yes & $4(25 \%)$ & 12 & 3.3 & $0.7-12.4$ & 0.18 & 0.94 & 3.0 \\
\hline & no & $18(10 \%)$ & 179 & & & & & \\
\hline \multirow{2}{*}{$\begin{array}{l}\text { 'Do you forget where you have } \\
\text { put things?' }\end{array}$} & yes & $6(19 \%)$ & 26 & 2.4 & $0.7-7.1$ & 0.27 & 0.86 & 1.9 \\
\hline & no & $16 \quad(9 \%)$ & 165 & & & & & \\
\hline \multirow{2}{*}{$\begin{array}{l}\text { 'Is it more difficult to remember } \\
\text { things than it used to be?' }\end{array}$} & yes & $13(17 \%)$ & 62 & 3.0 & $1.1-8.1$ & 0.59 & 0.68 & 1.8 \\
\hline & no & $9 \quad(7 \%)$ & 129 & & & & & \\
\hline \multirow{2}{*}{$\begin{array}{l}\text { 'Do you write reminders to yourself } \\
\text { more often now than before? }\end{array}$} & yes & $8(20 \%)$ & 33 & 2.7 & $0.9-7.6$ & 0.36 & 0.83 & 2.1 \\
\hline & no & $14 \quad(8 \%)$ & 158 & & & & & \\
\hline
\end{tabular}

\section{DISCUSSION}

The results show that elderly people with a subjective feeling of memory problems are at increased risk of developing dementia within the following three years. Depressive symptoms and an MMSE sumscore of 2427 are also independent risk factors, and the combined presence of all these at baseline gave an estimated probability of developing dementia within the following three years as high as 0.64 .

In this study, just over one third reported at least one memory problem on the ten GMS items. This is consistent with the French study by Gagnon et al. (20), in which $33.5 \%$ of a total sample of 2,715 nondemented, somewhat younger subjects than in our study (mean age 74.8 years), reported having problems in memorizing simple, new information. Also,
Bringel-Öhman et al. (21) found that $33 \%$ of 305 nondemented subjects (mean age 84.5 years) in the Swedish Kungsholmen project reported memory problems as measured by the Comprehensive Psychopathological Rating Scale (CPRS). Our study is, however, not consistent with the results of a Finnish study by Koivisto et al. (22), in which $76.3 \%$ out of a population of 1,049 persons (mean age 68.8 years) had subjective memory problems according to Memory Complaint Questionnaire (MAC-Q score). Although both demented and nondemented individuals were included, it can hardly explain the reported high prevalence.

The study by Flicker (8) included 59 persons with subjective memory impairment who had a follow-up examination after an average of 3.4 years. In contrast to our results, they found no decline in cognitive function at the follow-up examination. Taylor et al. (23)

Table 4. Estimated probability of new dementia within three years as a function of perceived memory, depressive symptoms, and MMSE sumscore at baseline, $\mathrm{N}=203$. $^{*}$

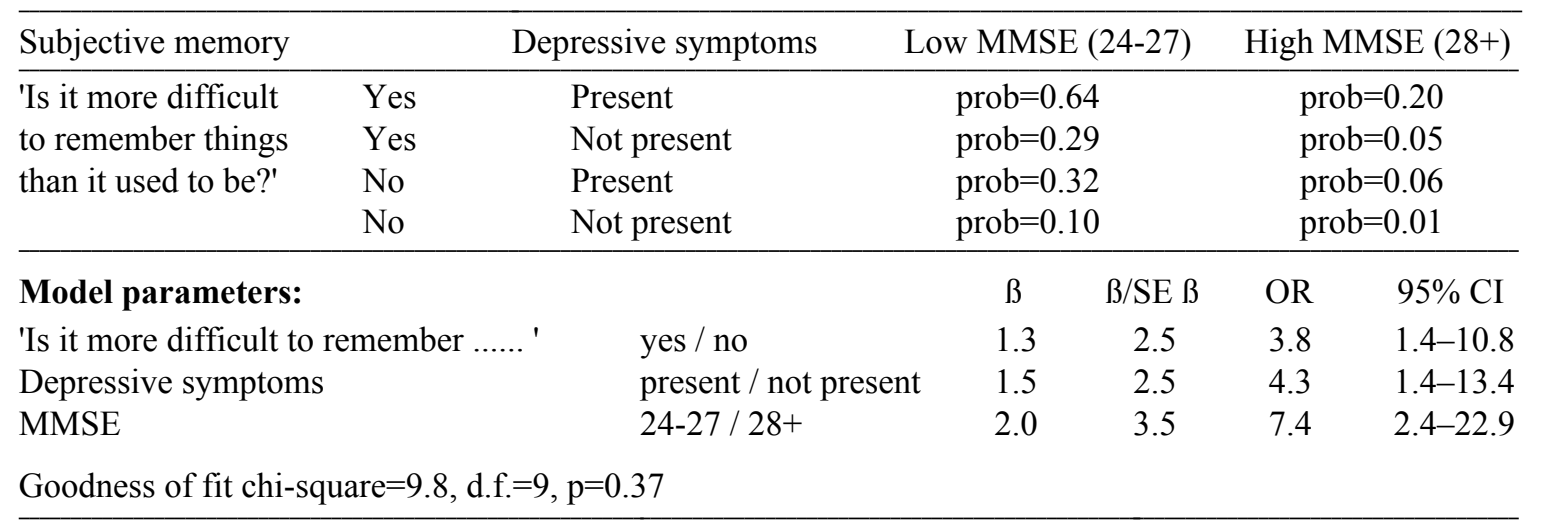

* Due to 10 subjects with missing data on the Beck instrument. 
noted a decline in memory performance during a fouryear period in 30 healthy elderly volunteers complai ning about memory problems, though the authors stated; 'We feel it is unlikely that these individuals are showing indications of early dementia'. By contrast, O'Brien et al. (9) reported development of dementia during three years in six out of 68 persons reporting memory problems, and this was found to be a slightly higher proportion than expected in a random population of elderly people. Bringel-Öhman et al. (21) also found that subjective memory complaints predict the development of dementia; $44 \%$ of their subjects with memory complaints $(\mathrm{N}=101)$ developed dementia compared to $17 \%$ of subjects without such complaints.

Except for a statistically significant association between one GMS item and new dementia diagnosed after 9 years $\left(\mathrm{T}_{3}\right)$, which probably is due to multiple statistical tests being made, an association between memory complaints and development of dementia was only valid within the first three years. This fits well in with the results of our previous study which showed that a low, but 'normal' score on the MMSE predicts the development of dementia within three, but not within 3-6 years (19). Masur et al. (24), who developed a model for predicting dementia consisting of different neuropsychological tests, showed that this model predicted dementia within three years very well, but had a very low ability to predict dementia after six years. The reason for this lack of predictability over more than three years probably is that perceived memory impairment relates to early dementia, and that a dementing process, when initiated, develops so rapidly that most sufferers with early symptoms will have a clear-cut dementia after three years.

Of the 10 subjective GMS-questions, the item 'Is it more difficult to remember things than it used to be?' proved to be the most sensitive regarding later development of dementia. This may reflect the fact that a change in mental function has started, even though the instruments used for cognitive testing are unable (low sensitivity) to detect these early changes (9).

Our results thus provide clues on how to identify elderly persons at an increased risk of developing dementia. Based on the results of this study, we think at least some examination regarding cognitive function and depressive symptoms should be made when elderly persons complain to their GP about a reduced memory function. The results of this assessment, if it is not pathological, can be regarded as a baseline level for later clinical follow-up.

\section{REFERENCES}

1. Bassett SS, Folstein MF. Memory complaint, memory performance, and psychiatric diagnosis: a community study. J Geriatr Psychiatry Neurol 1993; 6: 105-11.

2. Livingston G, Hawkins A, Graham N, et al. The Gospel Oak Study: prevalence rates of dementia, depression and activity limitations among elderly residents in Inner London. Psychol Med 1990; 20: 137-46.

3. Bolla KI, Lindgren KN, Bonaccorsy C, et al. Memory complaints in older adults. Fact or fiction? Arch Neurol 1991; 48: 61-4.

4. Hänninen T, Reinikainen KJ, Helkala EL, et al. Subjective memory complaints and personality traits in normal elderly subjects. J Am Geriatr Soc 1994; 42: 1-4.

5. Barker A, Carter C, Jones R. Memory performance, self-reported memory loss and depressive symptoms in attenders at a GP-referral and a self-referral memory clinic. Int J Geriatr Psychiatry 1994; 9: 305-11.

6. Grut M, Jorm AF, Fratiglioni L, et al. Memory complaints of elderly people in a population survey: variation according to dementia stage and depression. J Am Geriatr Soc 1993; 41: 1295-1300.

7. Christensen H. The validity of memory complaints by elderly persons. Int J Geriatr Psychiatry 1991; 6: 30712.

8. Flicker C, Ferris SH, Reisberg B. A longitudinal study of cognitive function in elderly persons with subjective memory complaints. J Am Geriatr Soc 1993; 41: 1029-32.

9. O'Brien JT, Beats B, Hill K, et al. Do subjective memory complaints precede dementia? A three-year followup of patients with supposed 'benign senescent forgetfulness'. Int J Geriatr Psychiatry 1992; 7: 481-6.

10. Henderson AS, Duncan-Jones P, Finlay-Jones RA. The reliability of the Geriatric Mental State Examination. Acta Psychiatr Scand 1983; 67: 281-9.

11. Engedal K, Gilje K, Laake K. Prevalence of dementia in a Norwegian sample aged 75 years and over living at home. Compr Gerontol A 1988; 2: 102-6.

12. American Psychiatric Association. Diagnostic and Statistical Manual of Mental Disorders, 3rd edn. Washington, DC: American Psychiatric Association, 1980. 
13. American Psychiatric Association. Diagnostic and Statistical Manual of Mental Disorders, 3rd edn., revised. Washington, DC: American Psychiatric Association, 1987.

14. Engedal K, Gilje K, Lilleaas F. Diagnostic evaluation of the mentally impaired elderly living at home. Scand $J$ Prim Health Care 1989; 7: 5-11.

15. Beck AT, Ward CH, Mendelson M, et al. An inventory for measuring depression. Arch Gen Psychiatry 1961; 4: $561-71$.

16. Montgomery SA, Aasberg M. A comprehensive psychopathological rating scale. Brit J Psychiatry 1979; 134: 382-9.

17. BMDP Statistical software. Berkeley: University of California Press, 1992.

18. Centers for Disease Control. Epi Info, version 3. Atlanta, 1988.

19. Braekhus A, Laake K, Engedal K. A low, 'normal' score on the Mini-Mental State Examination predicts development of dementia after three years. J Am Geriatr Soc 1995; 43: 656-61.

20. Gagnon M, Dartigues JF, Mazaux JM, et al. Self-reported memory complaints and memory performance in elderly French community residents: results of the PAQUID research program. Neuroepidemiology 1994; 13: 145-54.

21. Bringel-Öhman AS, Forsell Y, Grut M, et al. The relation between memory complaints, cognitive decline and development of dementia: longitudinal data from the Kungsholmen project, ageing and dementia. Proceedings of the Lancet conference, The Challenge of the Dementias, 1996, Edinburgh.

22. Koivisto K, Reinikainen KJ, Hänninen T, et al. Prevalence of age-associated memory impairment in a randomly selected population from eastern Finland. Neurology 1995; 45: 741-7.

23. Taylor JL, Miller TP, Tinklenberg JR. Correlates of memory decline: A 4-year longitudinal study of older adults with memory complaints. Psychol Aging 1992; 7: 185-93.

24. Masur DM, Sliwinski M, Lipton RB, et al. Neuropsychological prediction of dementia and the absence of dementia in healthy elderly persons. Neurology 1994; 44: 1427-32. 